\title{
INTRODUCTION TO THE DEPARTMENT OF pediatrics of shree BIRENDRA hospital. chHauni: Then AND NOW
}

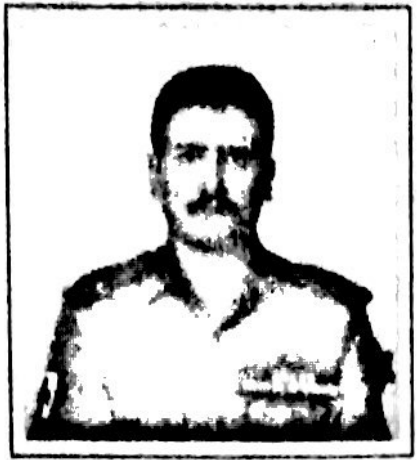

The department of pediatrics in The Royal Nepalese Army Medical Corps was established in 2045 BS, before which there were no Pediatricians. Brig Gen Dr Radha Shah then a Major started this department. It started as only an outpatient department and later had an insignificant share in the Inpatient department also. In 2047 BS after Shree Birendra Hospital was established this department got four beds as a mere share out of the Total 250 beds. By this time the department was joined by Col Dr Bishnu Thapa then a Major and then, followed by Lt Col Dr Arun Neopane. Soon it is expected to be joined by Maj Dr Hem Sagar Rimal who is in his final days as a postgraduate resident in Pediatrics in TUTH. Gradually over a period of 10 years the need for expansion was materialized by
Department of Pediatrics: Lt. Col. Dr. Arun Neopane,MD Consultant Pediatrician E Brig. Gen. Dr. Radha Shah,DCH Advisor, Pediatrics ECol. Dr. Bishnu Thapa,DCH HOD Dept of Pediatrics CS Maj. Dr. Hem Sagar Rimal,MBBS PG Trainee, Pediatrics

the construction of the family wing in the northwest part of the building of SBH and our dept got a bigger chunk of 22 beds with a separate wing of its own. All pediatric patients are catered for except Neonates, this is because we still do not have the neonatology wing and neither does the Gynaec/Obg dept conduct any deliveries in this hospital. At present this dept has taken strides and leaps in terms of its functioning both In and Outpatient departments as would be obvious from the various statistics shown as under.

Daily OPDs are conducted in TCMH complex situated in Mahankalsthan, where the average patients per day is about a hundred

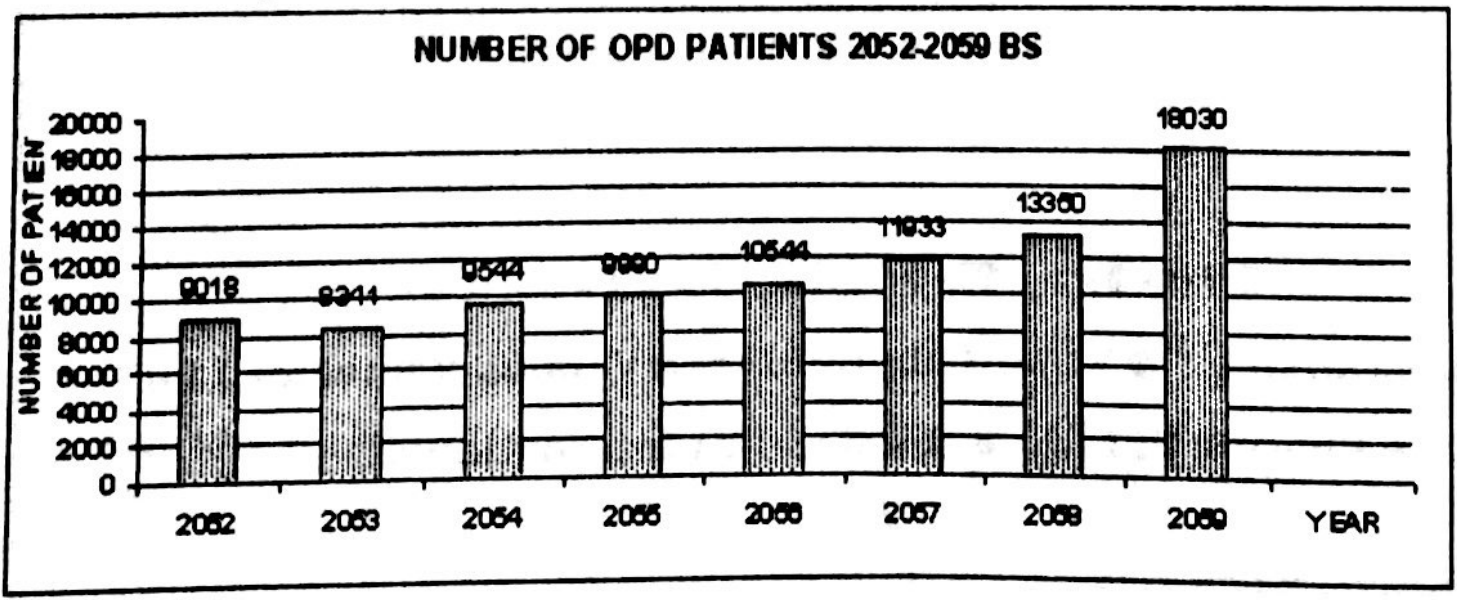


and the highest record has been 220 patients in a single day! Statistics for the same has been presented follow. All inpatients as per the are graphs, which
admitted in the pediatrics ward of Shree Birendra Hospital, Chhauni. The ward as such consists of 22 beds but can accommodate upto 25 patients in cáse of a rush. Presently there is a pediatric surgical and pediatric medical wing. There are two rooms for children of the officers and we also have a two-bedded PICU, which is a level II PICU. Most of the pediatric emergencies and critical care patients can be managed here. If a patient requires ventilatory support or continuous cardiac monitoring then they are referred to KCH PICU.

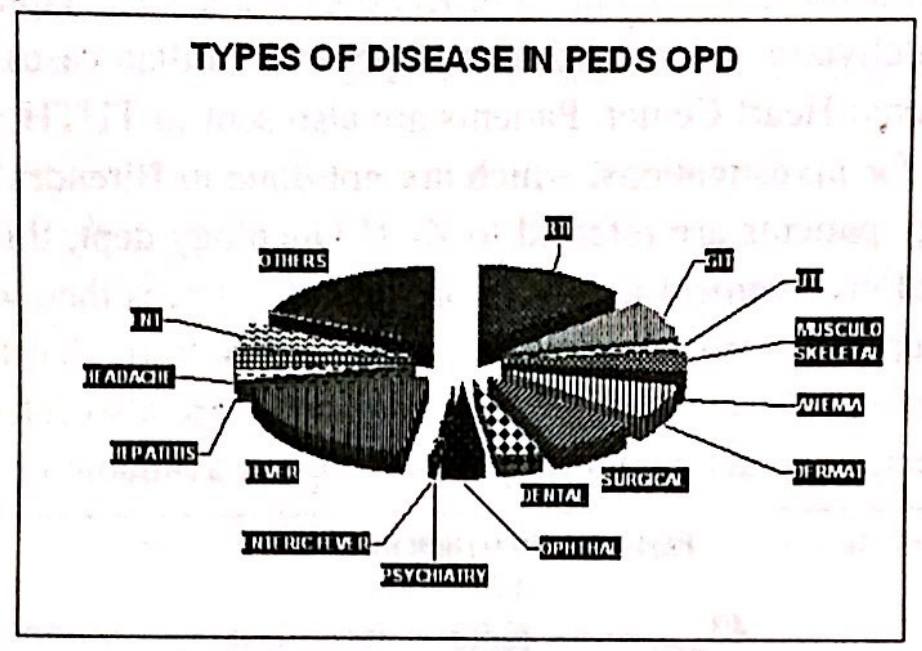

Programes:The Department of Pediatrics of Shree Birendra Hospital, Chhauni has been actively participating in the National Polio Eradication Program of Nepal. It is one of the surveillance centers for AFP case reporting. Various training programs concerning Polio eradication have been conducted here for doctors and paramedics of this hospital.

Vaccinations: All the vaccines in the Expanded Program on Immunization (EPI) are available in this department, we conduct vaccination days every Tuesday for children of serving and retired personals. We cover the six vaccine preventable diseases i.e. BCG, Polio, Diphtheria, Pertussis, Tetanus and Measles. Optional vaccine MMR is also available free of cost for children but other vaccines are only given if brought by the parents. The coverage statistics is quiet low and could be because deliveries are not conducted here and we do not have a neonatology department.

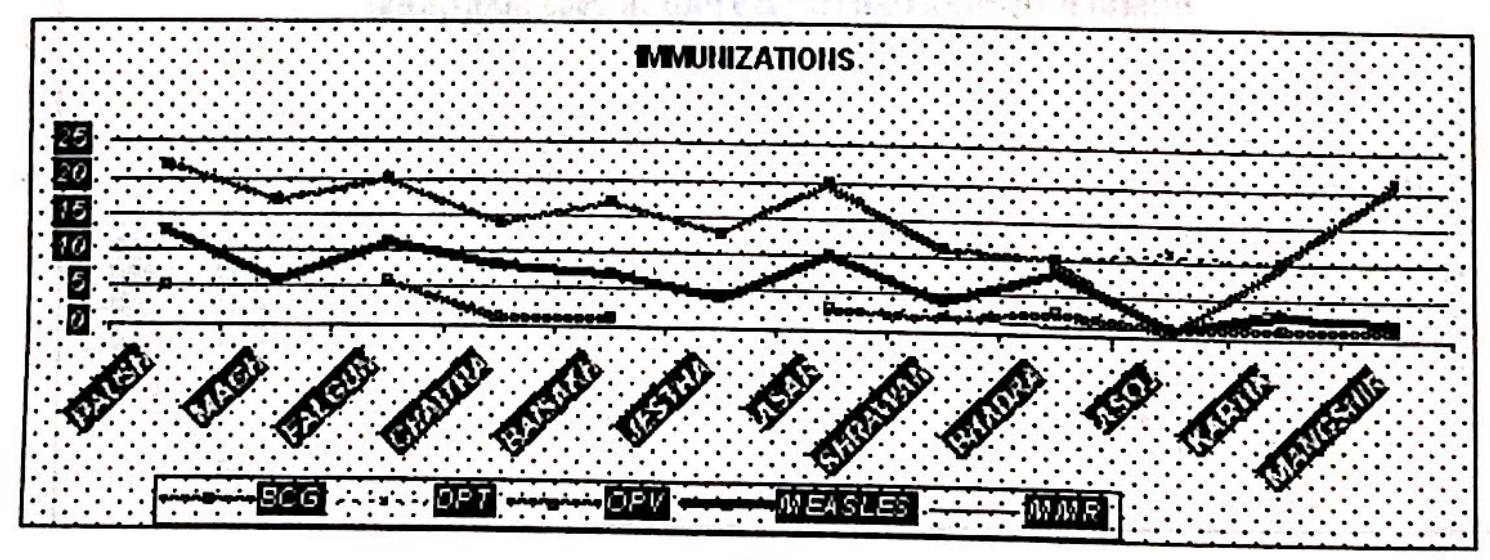




\section{MUSBH ANNNERSARY ISSUE-VOL V 2060}

Rehabilitation services: We have been taking the help of NGOs like the Sustha Manasthiti Kalyan Kendra in providing rehab services for our mentally and physically handicapped chil. dren. This has been done at a personnel level and we plan to make it official in the near future, taking the help of Army Wife's Welfare association (Adhikrit Shrimati Sangh). In this context it is worth mentioning that RNAOWA has been contributing financially for some of the mentally retarded children of serving personals. They have also been kind enough to help our department in building a playroom in the pediatric ward, providing toys and furnishing it.

Referrals: Apart from the intra hospital referrals we have also been referring cases to various other hospitals. We send all the neonates to Kanti Children's Hospital as we do not have a NICU nor are any deliveries conducted here. Operable cardiac cases are all referred to Shahid Gangalal National Heart Center. Patients are also sent to TUTH, Central lab (Teku) and even private labs for investigations, which are not done in Birendra Hospital. Some of the Pediatric Oncology patients are referred to $\mathrm{KCH}$ Oncology dept, this is because of the cost i.e. if the financial involvement is more than one lakh rupees then we have to take the help of $\mathrm{KCH}$ Onco dept who provide the rest of the money from charities and donations. Certain Neuro-surgery and Reconstructive surgery patients are also referred to Bir Hospital, as facilities for operating such pediatric patients are not available in our hospital.

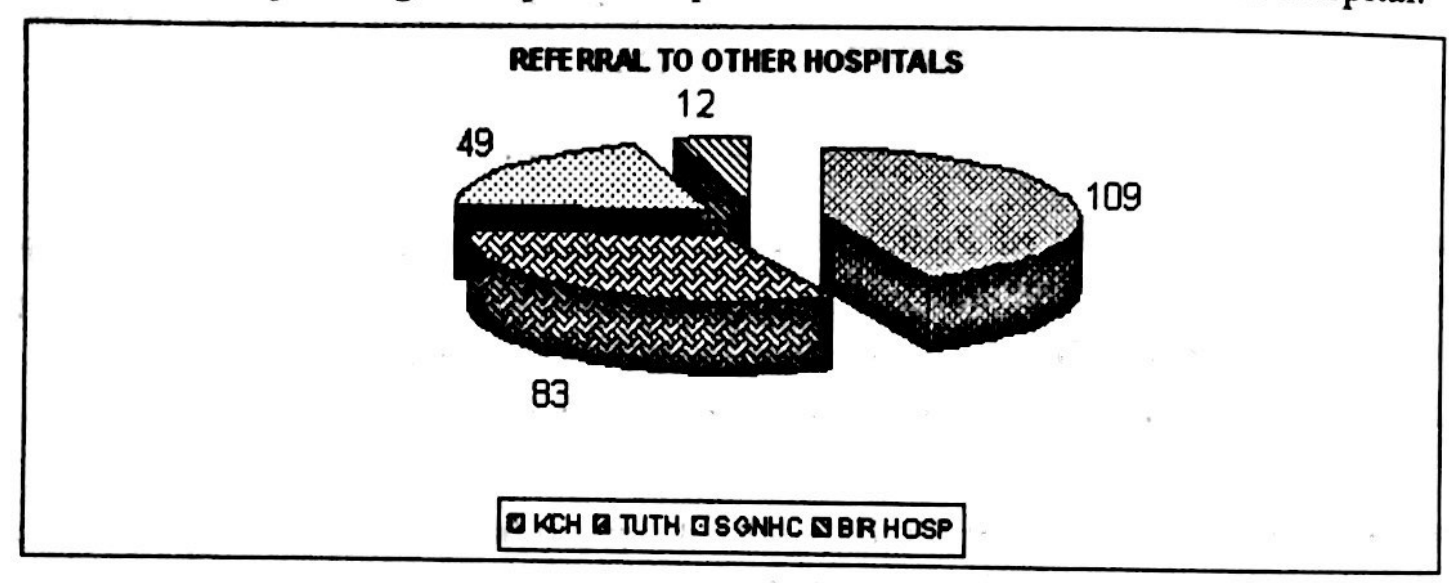

Library: Department of Pediatrics has got a small library of its own. Some of the books have been borrowed from the central library of Birendra Hospital but most of them are of the department itself. We plan to upgrade it further. All the standard pediatric textbooks are available in our library.

\section{Adimtted patients:}

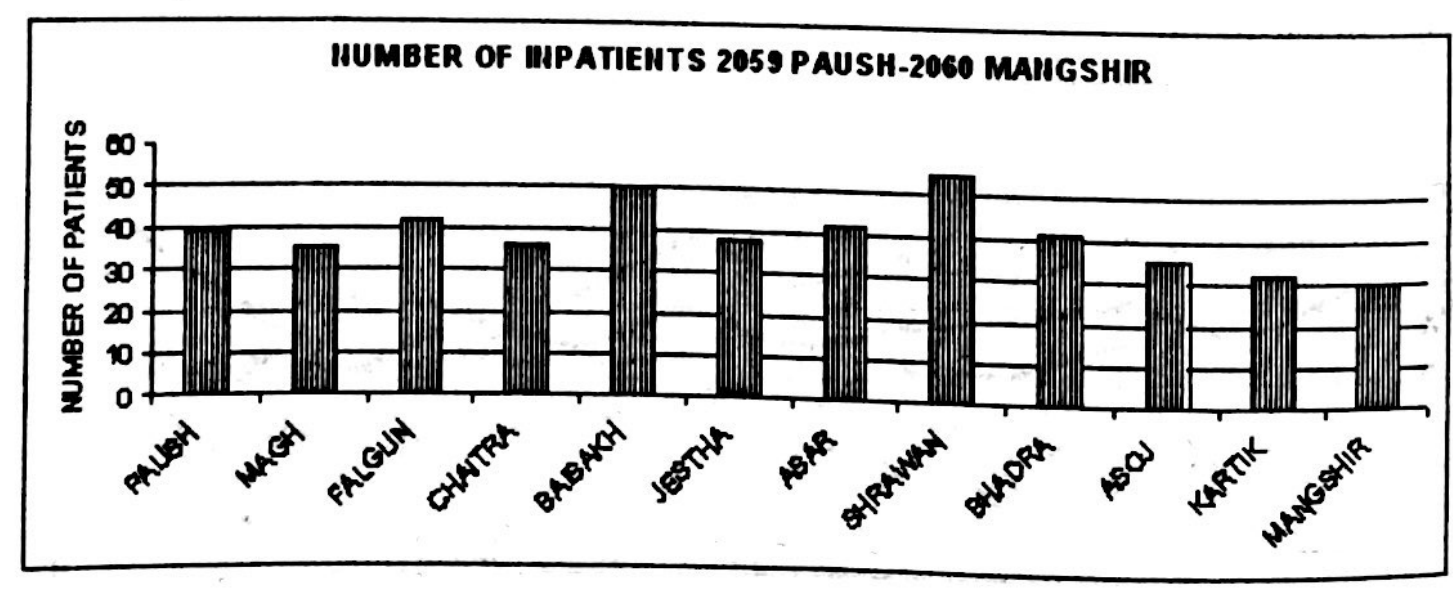


The breakup of patients admitted to the pediatric ward in the last one year is as given below:

1. GIT: Pain abdomen, Diarrhea, Indigestion,

2. Respiratory: Pneumonia, Pleural Effusion, Lung Abscess, Bronchitis, and Bronchial Asthma.

3. CVS: Congenital Heart Disease, RHD, Rheumatic fever, Congestive cardiac failure, Rhythm defects.

4. Oncology: Hodgkin's disease, Non Hodgkin's lymphoma, ALL, AML, Teratoma, Nephroblastoma.

5. Seizures: Febrile, Focal, Generalized, NCC, Neurodegenerative diseases, Congenital anomalies, Idiopathic.

6. CNS: Meningitis, Encephalitis, Cerebral Palsy, Ataxias, Chorea, Hydrocephalus, Spinal dysraphisms.

7. Nephrology: Congenital Nephrotic syndrome, Nephrotic syndrome, APSGN, Hematurias, SLE nephritis, other glomerulonephritis.

8. Hematology: Fe-deficiency anemia, Dimorphic anemia, Hereditary spherocytosis, Sickle cell anemia, Thallesemia, Hemophilia, ITP.

9. Viral fevers.

10. Surgical: Congenital hydrocoel, Congenital hernia, Head injuries, Abscesses, Appendicitis, Intestinal obstructions, Renal Calculi, BULLET and BLAST Injuries.

11. Orthopedics: Fractures, Dislocations, Tendon injuries, Amputations, Ligamentous injuries.

12. Eye: Congenital cataract, Eye trauma.

13. ENT: CSOM, Tonsillectomy, Nasal polyps.

14. Dental: Abscess, Cleft lip, Cleft palate.

15. Others: Malaria, Filaria, Hepatitis, Tuberculosis, Anasarca, Mumps, Measles, Hypothyroidism, Down syndrome, Drug reactions, Hysterias, Road traffic accidents, Malnutrition, Snake bite, Paracetamol and Caustic soda poisoning, Juvenile Rheumatoid Arthritis, Septic Arthritis, Henoch Scholen Purpuras.

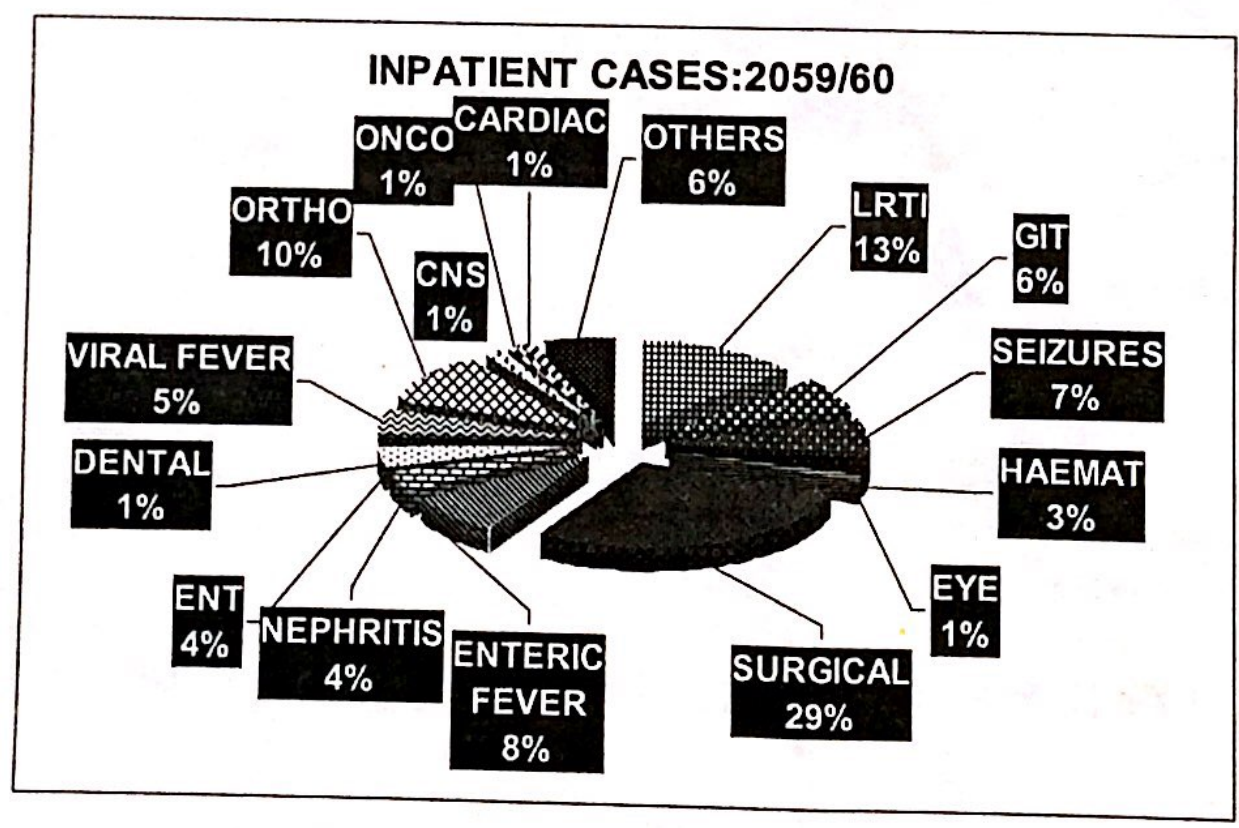

